\title{
The classification of esterases: an important gene family involved in insecticide resistance - A Review
}

\author{
Isabela Reis Montella ${ }^{1,2}$, Renata Schama ${ }^{1,2,3 /{ }^{+}}$, Denise Valle ${ }^{1,2,3}$ \\ 'Laboratório de Fisiologia e Controle de Artrópodes Vetores, Instituto Oswaldo Cruz-Fiocruz, \\ Av. Brasil 4365, 21040-900 Rio de Janeiro, RJ, Brasil ${ }^{2}$ Instituto de Biologia do Exército, Rio de Janeiro, RJ, Brasil \\ ${ }^{3}$ Instituto Nacional de Ciência e Tecnologia em Entomologia Molecular, Rio de Janeiro, RJ, Brasil
}

The use of chemical insecticides continues to play a major role in the control of disease vector populations, which is leading to the global dissemination of insecticide resistance. A greater capacity to detoxify insecticides, due to an increase in the expression or activity of three major enzyme families, also known as metabolic resistance, is one major resistance mechanisms. The esterase family of enzymes hydrolyse ester bonds, which are present in a wide range of insecticides; therefore, these enzymes may be involved in resistance to the main chemicals employed in control programs. Historically, insecticide resistance has driven research on insect esterases and schemes for their classification. Currently, several different nomenclatures are used to describe the esterases of distinct species and a universal standard classification does not exist. The esterase gene family appears to be rapidly evolving and each insect species has a unique complement of detoxification genes with only a few orthologues across species. The examples listed in this review cover different aspects of their biochemical nature. However, they do not appear to contribute to reliably distinguish among the different resistance mechanisms. Presently, the phylogenetic criterion appears to be the best one for esterase classification. Joint genomic, biochemical and microarray studies will help unravel the classification of this complex gene family.

Key words: metabolic resistance - carboxylesterase - classification history - insecticide resistance

Arthropods are the most abundant group of metazoans on our planet with estimates of greater than five million species (Ødegard 2000). As such, many species of metazoans are intimately linked to human life. Arthropodborne diseases, which have traditionally been a major public health problem in developing countries of tropical regions, are now spreading worldwide. Although these diseases were originally restricted to tropical areas, due to global warming and increased world travel, they are now following the rapid expansion of the habitat of their arthropod vectors into other regions. Additionally, many arthropod taxa are also agricultural pests or livestock parasites. Although the use of mechanical controls (e.g., the removal of breeding sites), biological controls (e.g., entomopathogenic bacteria or natural predators) and insect growth regulators is increasing, all control programs continue to extensively rely on the use of chemical insecticides to control vector or pest populations.

Where insects of public health importance are concerned, four major classes of insecticides are used: organochlorines, carbamates, organophosphates (OP) and pyrethroids (Nauen 2007). All of these insecticides target the insect central nervous system by interfering with the propagation of the nervous impulse at the synaptic

Financial support: CNPq, FAPERJ, CAPES, SVS, INCT-EM

(311313/2010-8, 150068/2010-7 to RS)

+ Corresponding author: schama@ioc.fiocruz.br

Received 3 February 2012

Accepted 10 April 2012 cleft or along the axon. The extensive use of insecticides for health and crop-related pests throughout the world has led to a global increase of insecticide-resistant populations, which is a serious concern for the majority of arthropod control programs.

To date, four major types of insecticide resistance mechanisms have been documented: point mutations in insecticide-targeted site genes, over-expression or mutations in the coding regions of detoxification enzymes, over-expression or mutations in genes involved in cuticle formation and behavioural changes (Whalon et al. 2008, Ranson et al. 2011). The main mechanisms described to date involve either point mutation in insecticide-targeted sites and/or more efficient detoxification mechanisms. The latter, also known as metabolic resistance mainly occurs due to an increase in the expression or activity of three major enzyme families: esterases (EST), glutathione-S-transferases and the cytochrome P450 superfamily of enzymes (Beaty \& Marquadt 1996, Hemingway \& Ranson 2000, Hemingway et al. 2004, Li et al. 2007, Braga \& Valle 2007, Russell et al. 2011). Measuring the activity of these enzymes in natural populations is an important step in monitoring insecticide resistance mechanisms worldwide and should be conducted together with the surveillance of control efficacy to prevent significant changes in susceptibility to the insecticides being used (Brogdon 1989, Brogdon \& McAllister 1998, 2004, Coleman \& Hemingway 2007, Polson et al. 2011).

Esterases deserve detailed attention because they can be involved in resistance to the leading chemicals that are extensively used by vector and pest-control programs (Li et al. 2007, Nauen 2007). An extensive and historic controversy regarding the nomenclature and classifica- 
tion of esterases is also noteworthy (Aldridge 1953a, Walker \& Mackness 1983, Walker 1993, Ranson et al. 2002, Satoh et al. 2002, Wheelock et al. 2005). This review attempts to convey the complexity of the different esterase classification criteria, highlighting the efforts of many authors to define a standard classification system that can be universally adopted. Esterase-derived metabolic resistance is a major problem in vector populations because it has already been correlated with resistance to the two major insecticide classes that are currently used, i.e., OPs and pyrethroids (Li et al. 2007, Hotelier et al. 2010, Bass \& Field 2011). Furthermore, metabolic resistance mechanisms are known to cause cross-resistance among insecticide classes and with other chemicals used for insect control (Oakeshott et al. 2005, Li et al. 2007, Nauen 2007, Carvalho et al. 2010, Farnsworth et al. 2010, Van Leeuwen et al. 2010).

Esterases: superfamily description and three-dimensional structure - Most esterases belong to the carboxylesterase (or carboxyl/cholinesterase, Pfam PF00135 domain) (Punta et al. 2012) gene family within the alpha/beta hydrolase fold protein (Pfam PF00561 domain) (Punta et al. 2012) superfamily (Hotelier et al. 2004, 2010). The alpha/beta hydrolase fold domain is found in a number of functionally different enzymes that are capable of hydrolysing a wide range of substrates (i.e., substrates with various chemical characteristics). For example, this superfamily includes proteases, lipases, esterases, dehalogenases, peroxidases and epoxide hydrolases, among others, and is one of the most common protein folds found in nature (Ollis et al. 1992, Nardini \& Dijkstra 1999, Hotelier et al. 2004).

The core of each carboxylesterase enzyme is an alpha/beta-sheet, rather than a barrel, containing eight strands connected by surrounding helices. Proteins of this family do not share a high degree of similarity in their primary DNA sequences and have widely differing substrate specificities. Nevertheless, due to their structural similarity and the conserved arrangement of residues in the catalytic site, esterases are thought to have originated from a common ancestor (Nardini \& Dijkstra 1999, Oakeshott et al. 2005). The canonical conformation of the alpha/beta hydrolase fold is composed of six alpha helices and eight beta-sheets in a parallel orientation, with the exception of the beta- 2 sheet that might not be in a parallel orientation in a few cases (Fig. 1). The fold is responsible for maintaining the juxtaposition of the residues of the catalytic site in the three-dimensional structure. These residues occur on loops and belong to a conserved triad containing a nucleophilic residue (serine, cysteine or aspartate), an acidic residue (glutamate or aspartate) and a histidine residue (Figs 1B, 3A). These amino acids are not contiguous in the primary sequence, but instead are found within separate 8-18residue regions of highly conserved amino acids (Myers
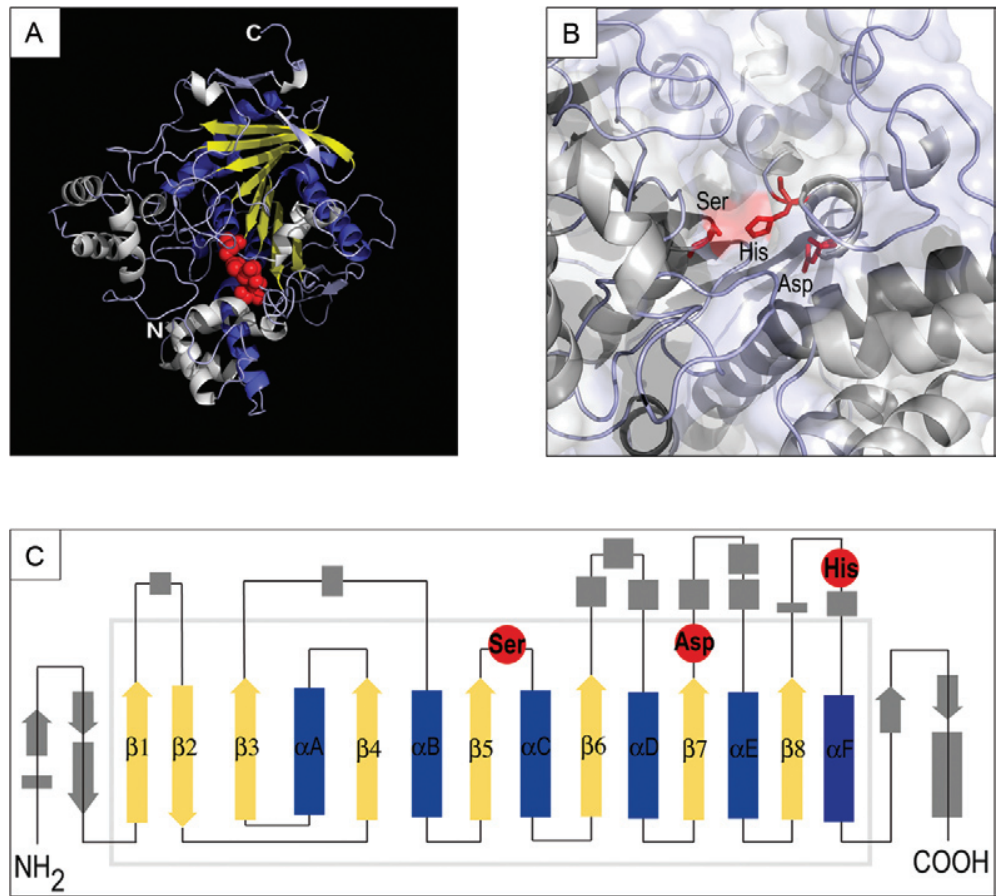

Fig. 1: Aedes aegypti AAEL005112 carboxylesterase gene. A: predicted secondary structure, alpha helices, beta strands and coils represented by helical ribbons, arrows and ropes respectively, carboxyl-terminal (C) and amino-terminal ends of the molecule (N); B: closer view of the catalytic triad, with catalytic residues in stick representation; C: topological diagram with alpha helices represented by arrows and beta strands by rectangles; the location of the catalytic triad is indicated. Alpha helices of the "canonical" alpha/beta hydrolase fold are in blue and beta strands in yellow, other secondary structures in gray. Catalytic residues in red: serine (Ser), histidine (His) and aspartic acid (Asp). Predicted architecture derived from homology modelling on PHYRE server (Kelley \& Sternberg 2009) based on the crystallographic structures of lepidopteran JHE and Drosophila acetylcholinesterase (Harel et al. 2000, Wogulis et al. 2006) among other available carboxylesterases. 
et al. 1988). The nucleophilic elbow, i.e., a sharp turn where the nucleophile is located (Fig. 1C), is the most conserved feature of the fold. Although all residues are necessary for hydrolytic activity, certain members of this hydrolase family lack one or all of the catalytic residues. These inactive members of the hydrolase structural family are involved in a number of different activities, such as surface recognition and other neurodevelopmental signalling processes (Oakeshott et al. 2005). Large insertions are tolerated provided that the relative positions of the triad residues are maintained. These insertions may contain a few amino acids or form a complete extra domain and this plasticity provides hydrolase superfamily members a remarkable capacity for adaptation and evolution, as has been shown for other enzymes (Aharoni et al. 2005, Khersonsky et al. 2006, Karve et al. 2010). The ESTHER database is an annotated collection of all published information related to the genes that encode proteins of this superfamily. A review by Wheelock et al. (2005) mentioned that 5,237 esterase-encoding nucleotide sequences were included in the ESTHER database,

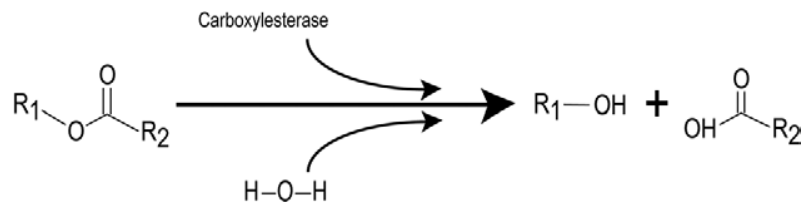

Fig. 2: basic carboxylesterase hydrolysis reaction. Carboxylesters are cleaved by carboxylesterases via the addition of water to form an alcohol and an acid metabolite. of which 318 were carboxylesterases (PF00135) (Punta et al. 2012). As of August 2011, there were 20,711 nucleotide sequences, of which 3,842 belong to the carboxylesterase gene family, thereby indicating an increased interest in this enzyme class.

This increased interest is due to the wide range of roles for these enzymes. Esterases are ubiquitous and important in the metabolism of several classes of exogenous and endogenous compounds. They perform a number of crucial functions in insect development and behaviour, such as odorant degradation and functions related to reproduction and digestion. Many important molecules, such as pheromones and other semiochemicals, are types of esters that are hydrolysed by esterases that, in insects, mainly belong to the carboxylesterase gene family. All catalytically active members of the insect carboxylesterase gene family use the same reaction mechanism, which involves a catalytic triad with a serine residue as a nucleophile (Fig. 1).

Hydrolysis mechanism and insecticide interaction The carboxylesterase gene family is a versatile family comprising proteins with highly specialised functions; some of these proteins have a strong substrate selectivity (such as juvenile hormone esterase and acetylcholinesterase), whereas others are less specific (commonly named esterases) or are non-catalytic proteins (such as neuroligins, gliotactins and neurotactins). The esterases are capable of hydrolysing ester bonds to generate an acid and an alcohol as metabolites (Fig. 2). This reaction is a two-step process (Figs 3, 4). The proposed catalytic mechanism involves nucleophilic attack by the catalytic serine hydroxyl on the carbonyl carbon of the ester bond

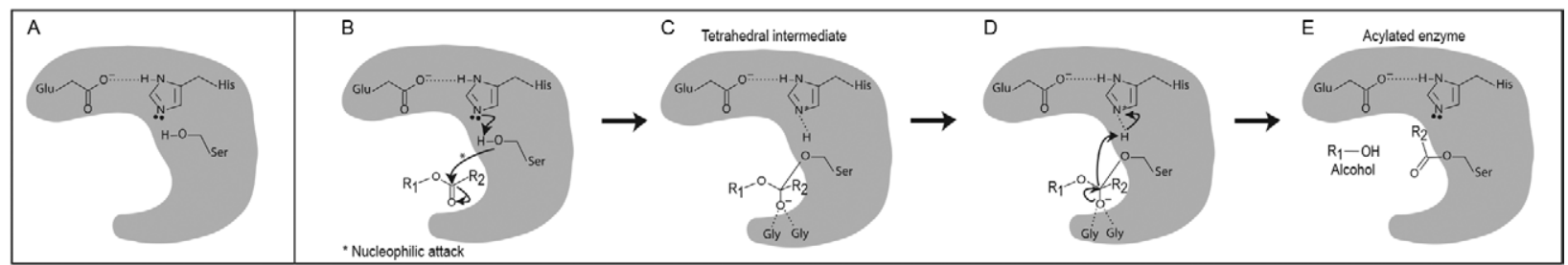

Fig. 3: first step of the carboxylesterase mediated hydrolysis reaction of a hypothetical carboxylester. A: a cartoon representation of the enzyme and its catalytic site; B: the reaction begins with the nucleophilic attack by the catalytic serine hydroxyl on the carbonyl carbon of the ester bond; C: making a tetrahedral intermediate. Two glycine residues are important in stabilizing the reaction and in maintaining the substrate in place; D, E: this first step of the reaction liberates the alcohol metabolite and the enzyme takes up an acylated form. Glu: glutamic acid; Gly: glycine; His: histidine; Ser: serine.

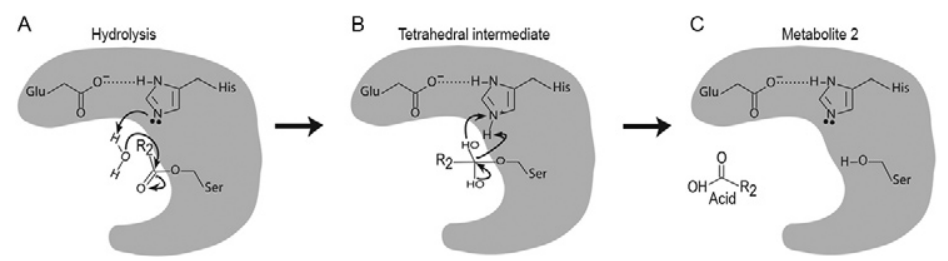

Fig. 4: second step of the carboxylesterase mediated hydrolysis reaction of a hypothetical carboxylester. A-C: a water molecule is needed for this step of the reaction and for the liberation of the acid metabolite and the enzyme goes back to its resting form. Glu: glutamic acid; Gly: glycine; His: histidine; Ser: serine. 
(Fig. 3B). The nucleophilicity of this hydroxyl group is increased and the reaction is stabilised through hydrogen bonding to the catalytic histidine (Fig. 3B-D). During the reaction, the histidine is stabilised by the carboxyl group of the acidic member of the catalytic triad. The first step (Fig. 3) liberates the alcohol metabolite with the enzyme becoming acylated (when the substrate is a carboxylic ester), carbamylated (when the substrate is a carbamic ester) or phosphorylated (when the substrate is a phosphoric ester) due to the covalent link between the acid moiety of the substrate and the serine residue (Fig. $3 \mathrm{E})$. The histidine residue's affinity to water molecules is an important part of the second step (Fig. 4) and enables the enzyme to return to its active state and release the acid molecule (Testa \& Kramer 2007, Russell et al. 2011). This hydrolysis step of the reaction is a common process among hydrolases and corresponds to a nucleophilic attack of water on the acylated enzyme and release of the acid moiety of the carboxylic ester and the free active enzyme (Ollis et al. 1992, Sogorb \& Vilanova 2002). Two glycines and other small residues around the oxyanion hole that are important in stabilising the transition between steps and in maintaining the substrate in place are conserved throughout the family. Esterases differ from lipases, another group of hydrolases that also preferentially hydrolyse ester bonds, by selectively acting on smaller, more hydrophilic substrates and by the absence of an additional movable helical lid that controls access to the active site (Verger 1997). A diverse range of carboxylic, thio, phospho and other esters can be substrates of esterases, although the energetics of the reactions differ substantially. These differences in substrate preference and specificity have been of major importance in esterase nomenclature and classification as described below.

A wide range of insecticides contain ester bonds (Fig. 5) and, therefore, they are susceptible to hydrolysis by esterase activity (Sogorb \& Vilanova 2002) (Figs 3, 4). Mutant esterases have often been implicated in target site and/or metabolic resistance to OP, carbamate and pyrethroid insecticides in pest insects and acarids [see Hotelier et al. (2010) for a review]. OP and carbamate target site resistance is mediated by mutations in acetylcholinesterase, which render it less sensitive to inhibition by the insecticide (Weill et al. 2004, Cassanelli et al. 2006, Liu et al. 2006, 2009, Ramphul et al. 2009, Kwon et al. 2010). Metabolic resistance involves either insecticide hydrolysis or sequestration by mutant carboxylesterases [see Bass and Field (2011) for a review]. Insecticide sequestration or enzyme inhibition occurs in the case of OPs because this class of insecticide serves as a good substrate for the first step of the hydrolysis mechanism (i.e., there is a covalent link between the enzyme and substrate) (Fig. 3), but is a poor substrate for the second step. The phosphorylated enzyme intermediate that forms via a reaction with an OP molecule is more stable than acylated or carbamylated enzymes (resulting from reactions with carboxylic and carbamic esters, respectively) and, therefore, the complete two-step hydrolysis reaction is very slow. The interaction of esterases with insecticides has been important for classification of these enzymes, as described below.
Classification schemes - The classification of esterases is complex and different nomenclatures have typically been adopted to describe these enzymes in one species or in a group of closely related species. Historically, insecticide resistance has driven research on esterases of insects and, therefore, most classification schemes focus on the catalytic properties of esterases and their interaction with insecticides.

Aldridge 1953 - Aldridge (1953a, b) proposed a classification system based on the interaction of esterases with OP molecules, such as E600 (diethyl p-nitrophenyl phosphate, also known as paraoxon). According to this classification system, esterases A (Est-A) are capable of hydrolysing OP compounds, esterases B (Est-B) are inhibited by them and esterases C (Est-C) do not interact with OPs. Aldridge believed that Est-A and Est-B had the same mechanism of interaction with OPs, with the major difference being the much slower rate of phosphorylated Est-B enzyme reactivation relative to Est-A (Walker \& Mackness 1983). Later, it was suggested that the serine residue present in the catalytic site of Est-B was susceptible to phosphorylation, which did not appear to occur for the equivalent residue of Est-A (Walker \& Mackness 1983). In 1968, Augustinsson also proposed that Est-A would have a cysteine residue instead of the serine nucleophile on the active site [as cited by Satoh et al. (2002)]. However, all insect carboxylesterases studied to date have serine residues as nucleophiles (Krejci et al. 1991, Anthony et al. 1995, Coutinho-Abreu et al. 2007, Yu et al. 2009, Li et al. 2010), thereby indicating that the ones that have a cysteine instead of serine in the active site are capable of hydroxylsing OPs might belong to a different domain.

Enzyme Commission 1978 - The Enzyme Committee classification system sponsored by the Nomenclature Committee of the International Union of Biochemistry and Molecular Biology (NC-IUBMB) classifies enzymes using a series of four numbers preceded by the letters EC (Enzyme Committee). The first three numbers indicate the following: (i) the type of reaction, (ii) the nature of the chemical bond and (iii) the broader nature of the substrate. The last number refers to the specific substrate that is recognised by the enzyme (Testa \& Kramer 2007). In the case of esterases, the numbers define the following classes: EC 3 - hydrolases (enzymes that promote a hydrolysis reaction), and EC 3.1 - hydrolases that act on ester bonds, e.g., esterases, lipases and exonucleases. With respect to the nature of the substrate, the esterases addressed here belong to two different classes. The first is called EC 3.1.1 (carboxylic ester hydrolases), which includes a wide range of carboxylic ester substrates and therefore enzymes such as acetylcholinesterase (the target of OP and carbamate insecticides) and other identified and unknown esterases. The second class, called EC 3.1.8 (phosphoric triester hydrolases), includes two specific enzymes: aryldialkylphosphatase (EC 3.1.8.1; Pfam PF02126 domain) (Punta et al. 2012) and diisopropyl-fluorophosphatase (EC 3.1.8.2; Pfam PF08450 domain) (Punta et al. 2012). It is important to note that both of the phosphoric triester hydrolases belong to completely different domains and have highly di- 


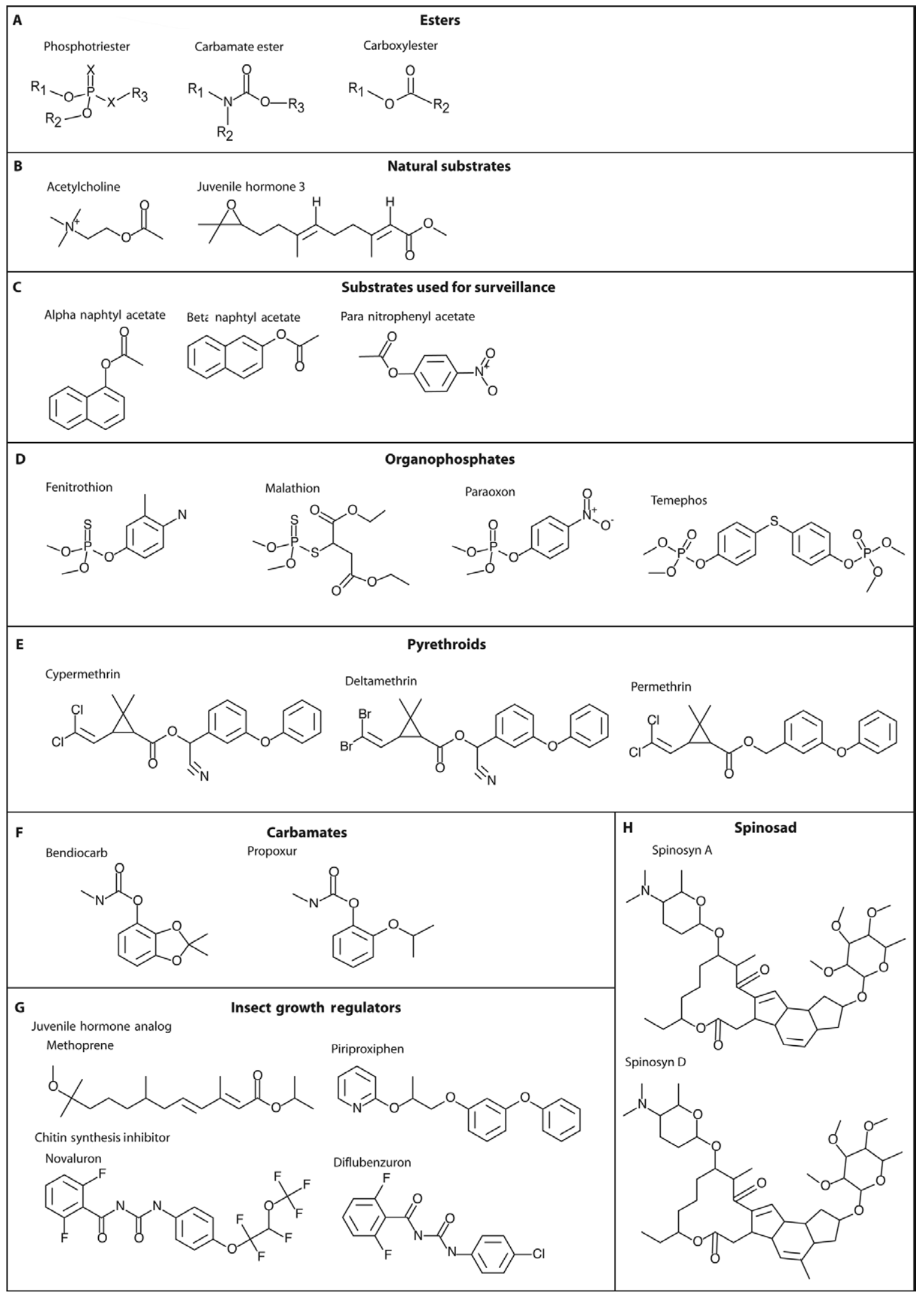

Fig. 5: chemical structure of a few carboxylesterase substrates and other insecticides. A: the three main types of esters dealt with in this review; B: two specific carboxylesterase natural substrates (acetylcholine, substrate for acetylcholinesterase and juvenile hormone III, substrate of juvenile hormone esterases); $\mathrm{C}$ : the three substrates used in biochemical surveillance assays that monitor insecticide resistance; D-H: chemical structure of some of the major insecticide classes used in vector control programs today. Pyrethroids, carbamates and organophosphates are esters and therefore mainly detoxified through hydrolysis. 
vergent architectures. Aryldialkylphosphatase is a triosephosphate isomerase (TIM) barrel metal ion-dependent enzyme that belongs to the amidohydrolase clan (Pfam CL0034 clan) (Punta et al. 2012). Diisopropyl-fluorophosphatase belongs to the beta-propeller clan (Pfam CL0186 clan) (Punta et al. 2012), whereas the carboxylic ester hydrolases belong to the alpha/beta hydrolase fold clan (Pfam CL0028 clan) (Punta et al. 2012).

In 1978, the NC-IUBMB proposed a new classification system (Walker \& Mackness 1983). Carboxylesterases (EC 3.1.1.1), also known as aliesterases, Est-B or carboxylic ester hydrolases, preferably act on organic molecules with open chains (i.e., aliphatic molecules). This preference is in contrast to that of arylesterases (EC 3.1.1.2), also called paraoxonases, Est-A or aryl-ester hydrolases, which preferentially act on aromatic compounds and are able to hydrolyse triester OPs. However, EC 3.1.1.1 enzymes are also capable of hydrolysing aryl ester compounds, whereas EC 3.1.1.2 enzymes can also hydrolyse open chain carboxylic esters, although these are not their preferred substrates.

According to the 1978 classification system, EC 3.1.1.2 enzymes are capable of hydrolysing phenyl acetate and other phenolic esters (such as paraoxon, a phenolic phosphotriester employed by Aldridge to classify esterases) [see section entitled Aldridge (1953)]. However, later evidence has suggested a more complex scenario. Esterases that were able to hydrolyse paraoxon, but not phenyl acetate were detected, and enzymes that could hydrolyse phenyl acetate or other phenolic esters, but not paraoxon were reported (Walker 1993). A parallel classification system emerged in an attempt to distinguish arylesterases, i.e., esterases that hydrolyse phenolic esters such as phenyl acetate, from Est-A (in Aldridge's classification) that hydrolyse triester OP compounds (Mackness et al. 1987, Reiner 1993). Mackness et al. (1987) used paraoxon and phenyl acetate as substrates to differentiate arylesterase activity (hydrolysis of phenyl acetate) from Est-A (hydrolysis of paraoxon). In human serum fractions, they found different peaks of activity with no overlap for the two substrates, thereby indicating that different enzymes were involved in each reaction. Table I summarises the classification schemes proposed up to 1984 .

Enzyme Committee 1989 - Further experiments were crucial to the modification of the esterase classification scheme by the NC-IUBMB in 1989 (Walker 1993). Since then, esterases that preferentially hydrolyse OP compounds, such as paraoxon (including those derived from phosphoric acid - $\mathrm{H}_{3} \mathrm{PO}_{4}$, which comprise most OP insecticides, and esters of phosphonic acid $-\mathrm{H}_{3} \mathrm{PO}_{3}$ ), are classified as EC 3.1.8.

EC 3.1.8 enzymes are phosphoric triester hydrolases, i.e., hydrolases that act on triester phosphorous bonds (Fig. 6). When these enzymes hydrolyse aryldialkylphosphates, producing dialkylphosphates and aryl alcohols, they are called Est-A (EC 3.1.8.1), paraoxonases, OP hydrolases or even aryldialkylphosphatases (the recommended name) among other listed names (Wheelock et al. 2005). These enzymes require divalent ions and are inhibited by chelating agents (Reiner 1993). EC 3.1.8.1 enzymes were previously identified as EC 3.1.1.2, which explains, in part, the confusion in the literature regarding the classification of esterases and Est-A in particular.

Currently, the terms Est-A and Est-B are used by different authors to distinguish between two groups of enzymes: those that hydrolyse OPs (Est-A) and those that are progressively inhibited by OPs (Est-B). This nomenclature, introduced by Aldridge (1953a, b), refers to groups of enzymes rather than individual ones. One important characteristic of the carboxylesterase gene family is that, especially in insects, a large number of duplications have occurred, and the high level of tolerance to alterations in their primary structure can cause dramatic changes in substrate specificity, thereby facilitating the functional diversification of the family (Oakeshott et al. 1999, Ranson et al. 2002, Aharoni et al. 2005, Strode et al. 2008, Hotelier et al. 2010).

Despite the divergence with respect to the classification of esterases, the consensus is that the enzymes called Est-B by Aldridge (i.e., those inhibited by OPs) belong to the family of serine esterases or carboxylesterases. In carboxylesterases, the serine residue of the enzyme's active site plays an important role in the hydrolysis reaction (Satoh et al. 2002, Wheelock et al. 2005, Satoh \& Hosokawa 2006). Some authors have suggested that the enzymes defined as Est-A (those that hydrolyse OPs) by Aldridge have certain peculiarities, such as the need for divalent ions and a cysteine residue instead of serine at the catalytic site (Satoh et al. 2002, Oakeshott et al. 2005, Wheelock et al. 2005, Satoh \& Hosokawa 2006), further emphasising that they might belong to a different gene family. The NC-IUBMB classifies both EC 3.1.1.2 (which hydrolyse carboxylic ester substrates) and EC 3.1.8.1 (which hydrolyse phosphotriester substrates) as Est-A, and Wheelock et al. (2005) observes that these two classes of enzymes hydrolyse OP compounds. Wheelock et al. (2005) also suggests that if the hydrolysis reaction occurs via an acy-

TABLE I

Summary of the classification schemes of esterases up to 1984

\begin{tabular}{lcccc}
\hline Name & Paraoxon inhibition & EC & Preference for aromatic compounds Preference for aliphatic compounds \\
\hline Esterase A or arilesterases & No & 3.1 .1 .2 & No & Yes \\
Esterase B or aliesterases & Yes & 3.1 .1 .1 & Yes & No \\
\hline
\end{tabular}

EC: Enzyme Committee 
lated cysteine at the active site, these Est-A should be classified as EC 3.1.8.1 (phosphoric triester hydrolase); however, if the reaction depends on a serine residue in this position, the enzyme should be classified as EC 3.1.1.2 (arylesterase). Table II shows the main discrepancies regarding the classification history of Est-A and Est-B.

Inhibition criterion - Although some esterases can be very specific, most have a wide and sometimes overlapping substrate range, thus leading to difficulties with respect to a classification system solely based on substrate specificity. Another proposed criterion relies on the use of three groups of inhibitors to discriminate amongst esterases: (i) sulphydryl reagents (mainly p-chloromercuribenzoate), (ii) OPs (such as paraoxon, diisopropyl fluorophosphate and fenitrooxon) and (iii) carbamate eserine sulphate. Four classes of esterases are distinguished using this scheme: (i) acetylesterases, which are not affected by any of the aforementioned inhibitors and have a preference for aliphatic substrates related to acetic acid, (ii) arylesterases, which are inhibited by sulphydryl reagents and have a preference for aromatic substrates, (iii) carboxylesterase, which are inhibited by organophosphorus compounds and have a preference for aliphatic esters (typically having a chain longer than acetic acid), and (iv) cholinesterases, which are simultaneously inhibited by OPs and eserine sulphate and have a preference for charged substrates (e.g., choline esters) instead of aliphatic and/or aromatic esters (Oakeshott et al. 1993).<smiles>[R]OC([R2])=O</smiles>

Carboxylester

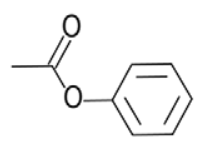

Phenylacetate<smiles>CC(=O)OCC[N+](C)(C)C</smiles>

Acetylcholine<smiles>[R]C(=O)OCC[N+](C)(C)C</smiles>

Acylcholine<smiles>[R]OP(=O)(O[R])Oc1c([R])c([R])c([R])c([R])c1[R]</smiles>
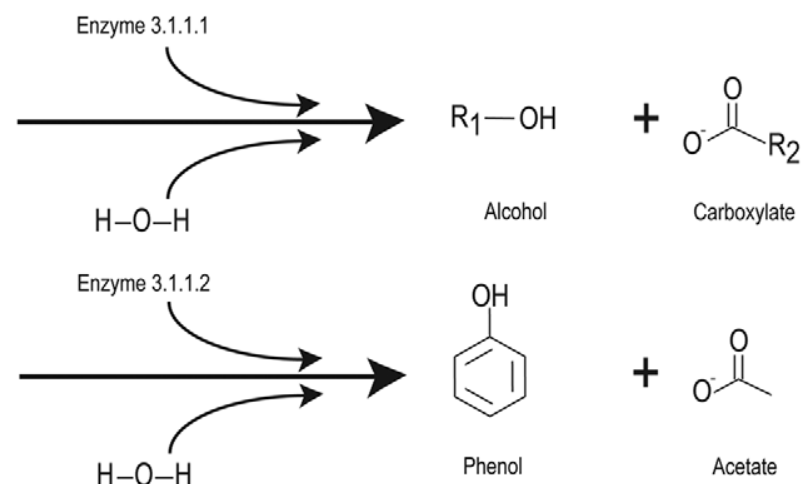<smiles>Oc1ccccc1</smiles><smiles>CC(=O)[O-]</smiles>
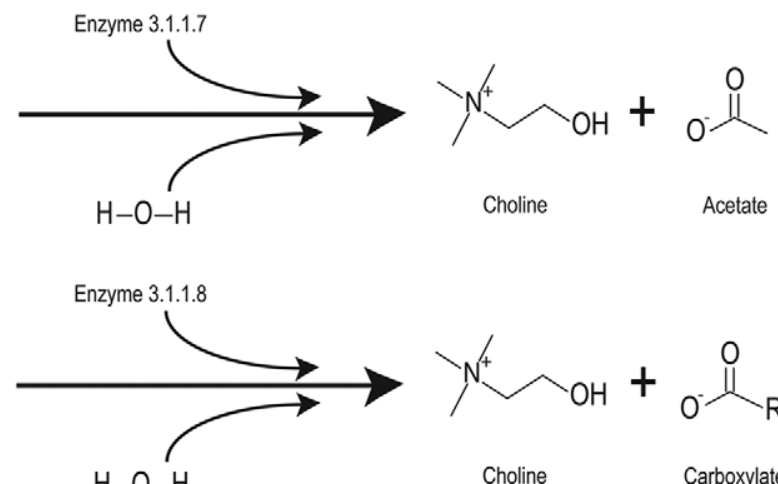<smiles>C[N+](C)(C)CCO</smiles><smiles>[R]C(=O)O[Na]</smiles>

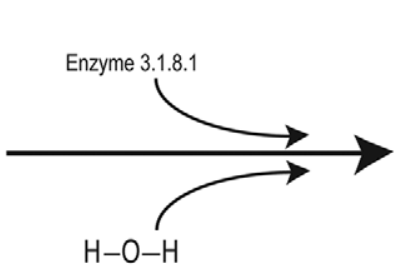<smiles>[R]c1c([R])c([R])c(O[AlH2])c([R])c1[R]</smiles><smiles></smiles>
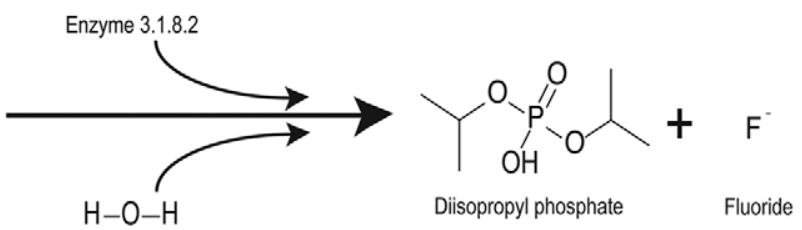

Fig. 6: hydrolysis reactions mediated by the different esterases as determined by the Nomenclature Committee of the International Union of Biochemistry and Molecular Biology. 
As an alternative functional criterion beyond those proposed above, these inhibition tests for the biochemical characterisation of esterases have been used to classify a variety of esterases, including those in insects of the genera Culex, Drosophila (Healy et al. 1991, Oakeshott et al. 1993) and Aedes (Lima-Catelani et al. 2004) as well as esterases of Arachnids, such as Rhipicephalus (Boophilus) microplus (Baffi et al. 2005), and plants (Carvalho et al. 2003).

Substrate and electrophoretic mobility criterion - A classification scheme based on the preferential hydrolysis of the artificial substrates alpha and beta-naphthyl acetate has been applied to categorise the esterase isozymes of Drosophila and mosquitos. For Culex esterases, whose relationship with insecticide resistance is widely studied, this alternative nomenclature combines the preference for the substrates alpha-naphthyl or beta-naphthyl acetate with the electrophoretic mobility of the enzymes (Hemingway \& Karunaratne 1998). This nomenclature has no connection with the Est-A and Est-B designation described above, as both alpha and beta naphthyl substrates are carboxylic esters. Esterases that hydrolyse alpha and beta-naphthyl acetate are designated A and B, respectively. Each enzyme allele is assigned a number according to its position following electrophoresis under non-denaturing conditions (Hemingway \& Karunaratne 1998). However, with the increasing number of described esterases, it became impossible to distinguish these enzymes using this approach. To overcome this difficulty, it was decided that the enzymes that specifically hydrolyse alpha or beta-naphthyl acetate would be designated Est $\alpha$ and Est $\beta$, respectively. A superscript number would indicate the alleles and therefore the different nucleotide sequence of each new variant (Vaughan \& Hemingway 1995, Hemingway \& Karunaratne 1998). The use of the electrophoretic mobility of isozyme alleles for enzyme classification does not have systematic value because 20$30 \%$ of the existing variability is hidden within the different alleles (Thorpe 1982, 1983), and thus, many variants cannot be identified. In addition, although most isozymes have a preferred substrate, typically a wide range of compounds can be hydrolysed and the use of a classification based on these two substrates (i.e., alpha and beta-naphthyl acetate) is extremely limited (Zouros \& van Delden
1982). Another problem is the need to discriminate between esterases that are capable of hydrolysing or sequestering insecticides because the ability to predict the presence of such enzymes in natural vector populations is of great importance in vector control programs.

Mackness et al. (1987) and Mentlein et al. (1985) attempted to differential the different esterase isoforms based on substrate specificity. However, this type of classification became overwhelming due to the large spectrum of substrates that can be hydrolysed by esterases. Although these classification systems have little value as predictors of enzyme function, they are still used in vector control programs for the determination of insecticide resistance in natural populations, as described below.

Phylogenetic/genomic criterion - Satoh and Hosokawa (1995) suggested the use of nucleotide sequence similarity of carboxylesterase-encoding genes as a criterion to distinguish amongst mammalian carboxylesterase isozymes and classified them into five families, i.e., CES1-CES5. CES1, for example, includes the major mammalian carboxylesterases and $43 \%$ of the human isoforms. For insects, Oakeshott et al. (2005) proposed a system for the phylogenetic classification of carboxylesterases that divides the family into 14 clades (A-N) that are largely (but not always) monophyletic within three classes (Fig. 7). These classes are differentiated based on the phylogenetic similarity of carboxylesterases genes as well as a number of different physiological characteristics, such as catalytic competence and cellular localisation (identified by the presence of N-terminal signal peptides). Proteins that lack the catalytic triad (indicative of a lack of catalytic function) are grouped in the neurodevelopmental carboxylcholinesterases (neuro/ developmental class) (Fig. 7) class comprising clades L, $\mathrm{M}$ and $\mathrm{N}$, which correspond to the neuroligin, gliotactin and neurotactin lineages, respectively. This class also includes two clades of uncharacterised proteins (I and $\mathrm{K})$ as well as the catalytic active acetylcholinesterases (clade J). Proteins of this class are often membrane-associated and are catalytically inactive (with the exception of clade J). A second class contains clades D-H and generally includes secreted enzymes that have specific substrates, such as hormones and pheromones (hormone/semiochemical processing class). The third class

TABLE II

Main disagreements on the classification history of esterases A and B

\begin{tabular}{|c|c|c|c|c|c|c|}
\hline \multirow[b]{2}{*}{ EC/classification scheme } & \multirow[b]{2}{*}{ Aldridge $^{a}$} & \multirow[b]{2}{*}{ Wheelock $^{b}$} & \multicolumn{2}{|c|}{ Organophosphates hydrolysis } & \multicolumn{2}{|c|}{ Substrate preference } \\
\hline & & & Wheelock $^{b}$ & IUBMB & Wheelock $^{b}$ & IUBMB \\
\hline 3.1.1.1/3.1.1.7/3.1.1.8 & B & B & No & No & Carboxylic ester & Carboxylic ester \\
\hline 3.1.1.2 & A & A & Yes & No & Phosphotriester & Carboxylic ester \\
\hline 3.1.8.1 & A & A & Yes & Yes & Phosphotriester & Phosphotriester \\
\hline
\end{tabular}

$a$ : Aldrige (1953a, b); $b$ : Wheelock et al. (2005); EC: Enzyme Committee; IUBMB: Nomenclature Committee of the International Union of Biochemistry and Molecular Biology 
contains clades A, B and C and includes intracellular enzymes with dietary and detoxification functions (dietary/detoxification class). Mutant enzymes that confer insecticide resistance occur in all three classes.

The amino acid identity of carboxylesterases compared to other members of the alpha/beta hydrolase fold superfamily is very low despite their functional and structural similarities. Even among the major lineages of carboxylesterases, amino acid identity values can be as low as 20\% (Oakeshott et al. 1999). Only a few insect carboxylesterase lineages (within the neuro/developmental class) are homologous to vertebrate carboxylesterase lineages, thereby indicating that the diversification of this family in insects appears to have occurred after their divergence from vertebrates and, possibly, nematodes (Oakeshott et al. 2005).

The molecular study of several insect species has shown that all classes and most clades are represented, although the number of genes in each clade varies widely. The widespread representation of the clades indicates that most of the major clades are older than the split between Holometabola and Hemimetabola (Oakeshott et al. 2005). For example, the honeybee Apis mellifera, an insect known to have relatively few detoxification genes, has 10 (Claudianos et al. 2006) of the 14 clades recognised by Oakeshott et al. (2005). The majority of the metabolic insecticide resistance genes have been reported to occur in the dietary/detoxification and hormone/semiochemical classes, whereas the neuro/ developmental class has been implicated in target site insecticide resistance. For example, in mosquitoes of the genera Anopheles and Aedes, microarray experiments have shown that genes from clades $\mathrm{A}$ and $\mathrm{F}$ (juvenile hormone esterase and other secreted esterases) were up- regulated in insecticide-resistant populations (Vontas et al. 2007, Poupardin et al. 2008, Strode et al. 2008, Riaz et al. 2009, Saavedra-Rodriguez et al. 2011).

A phylogenetic classification scheme may become especially useful as additional sequences are added to the database. The work of Oakeshott et al. (2005) was the first to propose a phylogenetic classification criterion for the carboxylesterase gene family and although many authors have used this criterion, a better understanding of the physiological function of the enzymes in each clade is still warranted.

Insecticide resistance - Insecticide resistance monitoring programs are of critical importance if chemical controls continue to be used as a part of integrated pest management strategies. For this reason, it is important to understand the molecular basis of insecticide resistance and vector control procedures. Insecticide resistance can be detected at many levels and historically has been investigated using bioassays and biochemical detection methods (Braga et al. 2004, 2005, da-Cunha et al. 2005, Valle et al. 2006, Braga \& Valle 2007, Montella et al. 2007, Polson et al. 2011). Although these methods are extensively used, they are gradually being replaced by molecular techniques such as polymerase chain reaction (PCR)-based mutation analysis and microarray methods (reviewed in Coleman \& Hemingway 2007, Hotelier et al. 2010, Bass \& Field 2011).

Insecticide resistance derived from metabolic detoxification can develop in natural populations in three different ways: gene amplification (gene duplication), the up-regulation of gene expression and genetic mutations in coding regions (Hemingway et al. 1998). Resistance driven by the amplification of genes coding for esteras-

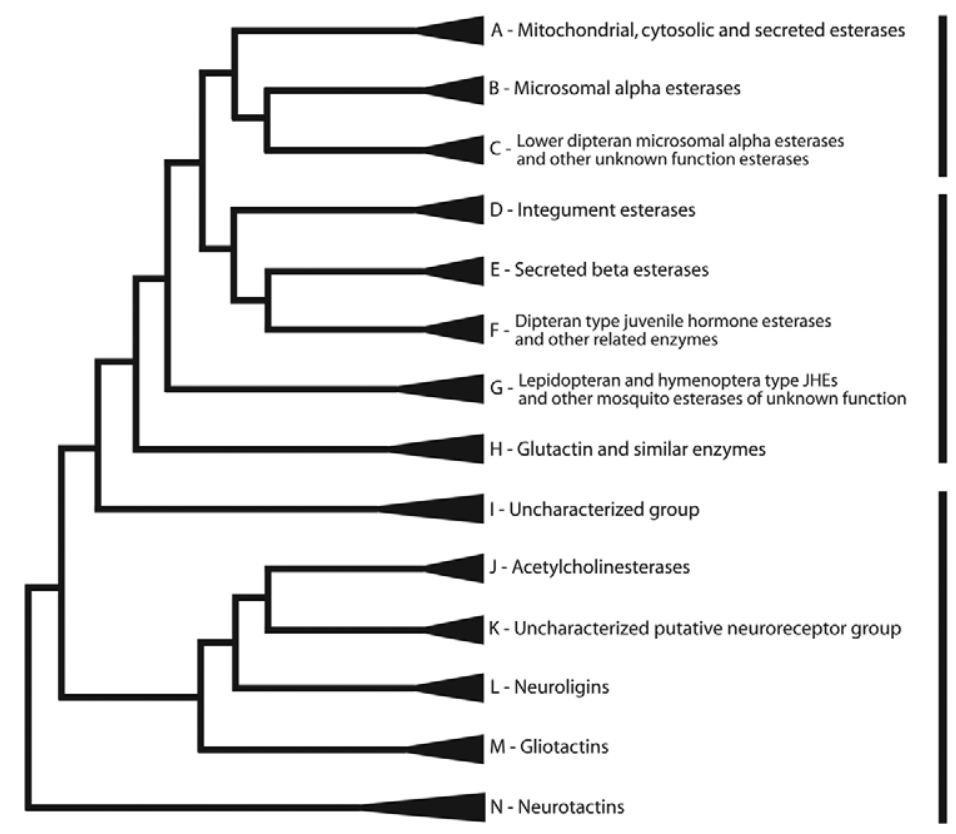

dietary/detoxification class

hormone/semiochemical processing class

neuro/developmental class

Fig. 7: a schematic representation of the phylogenetic clades proposed by Oakeshott et al. (2005). Clade names adapted from Oakeshott et al. (2005, 2010), Claudianos et al. (2006), Strode et al. (2008) and Yu et al. (2009). 
es, whereby a gene that is typically found as a single copy in susceptible organisms is present in multiple copies in resistant organisms, has been implicated in the enhanced degradation and/or sequestration of OPs, carbamates and pyrethroids and has been detected in both Diptera and Hemiptera (Raymond et al. 1998, Field et al. 1999, Li et al. 2007, 2009, Bass \& Field 2011). Altered gene expression, whereby resistant organisms can produce a greater number of gene products than susceptible organisms, has been detected in the orders Hemiptera, Hymenoptera, Lepidoptera and Diptera (Li et al. 2007, Bass \& Field 2011). Finally, mutations in carboxylesterase gene-encoding domains have been detected in Diptera, Hymenoptera and Lepidoptera and, in some cases, these mutations lead to increased OP hydrolysis and/or sequestration (Li et al. 2007, Hotelier et al. 2010). For example, Newcomb et al. (1997) found that a single amino acid substitution converts a carboxylesterase to an organophosphorus hydrolase in the blowfly Lucilia cuprina. Target site-based insecticide resistance in acetylcholinesterase genes has been thought to occur only due to mutations in the coding region, which confers a lower sensitivity with respect to the insecticide as well as the natural acetylcholine substrate, thereby causing some loss of fitness (Weill et al. 2004). However, mutations that alter the GPI anchor in acetylcholinesterase genes in the olive fruit fly (Kakani et al. 2011) and acetylcholinesterase gene duplication in the two-spotted spider mite (Kwon et al. 2010) were recently detected. In both cases, the consequences of these mutations are increased enzymatic activity and improved tolerance to OPs.

Genomic and phylogenetic studies are elucidating the complexity of insect detoxification enzyme families, thereby providing a greater understanding of metabolic resistance to insecticides and its genetic basis. In insects, the carboxylesterase gene family appears to comprise the main esterases involved in insecticide metabolism, although other esterases with different domains may be involved. For example, Scanlan and Reid (1995) have described a phosphotriesterase in soil bacteria that has a TIM barrel domain with a phosphate-binding site but lacks the alpha/beta hydrolase fold domain commonly found in insect esterases. Consequently, the transgenic expression of this bacterial enzyme confers OP resistance in both Drosophila melanogaster and Spodoptera frugiperda (Dumas et al. 1990, Benedict et al. 1994). Nevertheless, the extent to which the expression of native insect phosphotriesterase is associated with OP resistance in natural populations is not yet known. Zhu et al. (2011) have found that an enzyme homologous to a salmon phosphotriesterase was present in the transcriptional profile of the tobacco budworm and was implicated in the insecticide resistance of this organism. However, early esterase studies addressed alpha and beta-naphthyl acetate substrates and it is still not clear how many of these isozymes actually belong to the carboxylesterase gene family. For example, although all seven of the $\mathrm{He}$ licoverpa armigera isozymes identified by Teese et al. (2010) belonged to the carboxylesterase gene family, Healy et al. (1991) found that three out of the 22 identified D. melanogaster esterase isozymes did not. Inter- estingly, Hemingway (2000) argued that despite the high levels of malathion resistance in Anopheles populations, an increase in esterase activity was not observed in mosquito homogenates when conventional alpha and betanaphthyl acetate substrates were used. Montella et al. (2007) have also reported conflicting results when using alpha and beta-naphthyl acetate and para-nitro phenyl acetate (a supposedly broader substrate) as substrates for the routine monitoring of insecticide resistance of $\mathrm{Ae}$ des aegypti populations in Brazil. These results indicate that newer and more specific substrates are needed when biochemical assays are used to screen for insecticide-resistant populations in the field.

The carboxylesterase gene family appears to be rapidly evolving and each insect species has a unique complement of detoxification genes with only a few orthologues across species (Ranson et al. 2002, Oakeshott et al. 2003, 2010, Claudianos et al. 2006, Strode et al. 2008). As described above, this family comprises a mixture of highly specialised enzymes with specific substrates, but also includes less-selective members with broad and often overlapping ranges of substrates. Protein families that are commonly associated with drug resistance or degradation, such as carboxylesterases, have been thought to evolve rapidly. It has been shown that these types of proteins can accumulate a large number of mutations without affecting their native function. In fact, this process appears to give them a selectivity advantage for being less selective (Aharoni et al. 2005, Khersonsky et al. 2006). Microarray experiments (Vontas et al. 2007, Poupardin et al. 2008, Strode et al. 2008, Riaz et al. 2009, SaavedraRodriguez et al. 2011) have confirmed that metabolic resistance to insecticides involves complex mechanisms and various resistant populations have developed unique mechanisms to cope with toxins present in their habitats. Indeed, the rapid and species-specific expansion of detoxification gene families in insects indicates that gene redundancy has resulted in a high rate of diversification, which might be responsible for the differences observed among populations.

Despite all efforts to develop an improved system for the classification of esterases, a universal standard has yet to be defined. The examples listed above cover different aspects (e.g., the preference for substrates, the primary structure of the protein and the catalytic site as well as molecular characteristics, such as nucleotide homology) in an attempt to find a single method for classifying esterases. However, these systems do not appear to be enabling the development of a universal standard because various studies use different classification criteria for the same enzymes, as discussed throughout this review. For example, the majority of researchers studying insecticide resistance use the nomenclature that has been applied to the mosquito genera Culex based on the use of the substrates alpha and beta-naphthyl acetate. Although they are inexpensive and easy to use, classifications based on these substrates do not distinguish between the vast varieties of esterase isoforms in insects and have been shown to produce conflicting results regarding insecticide resistance in natural and laboratory populations. Therefore, it is important that new and improved 
methods are used to distinguish between different metabolic resistance mechanisms. Presently, the phylogenetic criterion appears to be the best metric for the classification of esterases, especially with the increased use of sequencing techniques. Joint genomic, biochemical and microarray studies appear to be the best approaches for establishing a consistent understanding and classification of this complex gene family. The molecular/genomic analysis of non-carboxylesterase isozymes, structural studies of other carboxylesterase clades and further functional characterisation of the different genes within the carboxylesterase family are priorities for future work. We expect that on-going genomics, proteomics and metablomics projects will be essential for improving the understanding of the importance of carboxylesterases in the adaptation of insects to new ecological niches as well as the role of esterase isoforms in specific metabolic pathways. This "omics" approach will allow for the quantification of carboxylesterase genes within the main insect clades and will help to reveal how and where these genes are expressed. Therefore, the future promises exciting developments in the science of insect biochemistry and metabolism.

\section{ACKNOWLEDGEMENTS}

To RM Albano, for a critical reading of the manuscript.

\section{REFERENCES}

Aharoni A, Gaidukov L, Khersonsky O, Gold SM, Roodveldt C, Tawfik DS 2005. The 'evolvability' of promiscuous protein functions. Nat Genet 37: 73-76.

Aldridge WN 1953a. Serum esterases. I. Two types of esterase (A and B) hydrolysing p-nitrophenyl acetate, propionate and butyrate and a method for their determination. Biochem J 53: 110-117.

Aldridge WN 1953b. Serum esterases. II. An enzyme hydrolysing diethyl p-nitrophenyl phosphate (E600) and its identity with the A-esterase of mammalian sera. Biochem J 53: 117-124.

Anthony N, Rocheleau T, Mocelin G, Lee H-J, Ffrench-Constant R 1995. Cloning, sequencing and functional expression of an acetylcholinesterase gene from the yellow fever mosquito Aedes aegypti. FEBS Letters 368: 461-465.

Baffi MA, Pereira CD, Souza GRL, Bonetti AM, Ceron CR, Gourlart LR 2005. Esterase profile in a pyrethroid-resistant Brazilian strain of the cattle tick Boophilus microplus (Acari: Ixodidae). Genet Mol Biol 28: 749-753.

Bass C, Field LM 2011. Gene amplification and insecticide resistance. Pest Manag Sci 67: 886-890.

Beaty BJ, Marquadt WC 1996. The biology of disease vectors, University Press of Colorado, Colorado, $632 \mathrm{pp}$.

Benedict MQ, Scott JA, Cockburn AF 1994. High-level expression of the bacterial opd gene in Drosophila melanogaster: improved inducible insecticide resistance. Insect Mol Biol 3: 247-252.

Braga IA, Lima JBP, Soares SS, Valle D 2004. Aedes aegypti resistance to temephos during 2001 in several municipalities in the states of Rio de Janeiro, Sergipe and Alagoas, Brazil. Mem Inst Oswaldo Cruz 99: 199-203.

Braga IA, Mello CB, Montella IR, Lima JBP, Martins-Jr AJ, Medeiros PFV, Valle D 2005. Effectiveness of methoprene, an insect growth regulator, against temephos-resistant Aedes aegypti populations from different Brazilian localities under laboratory conditions. J Med Entomol 42: 830-837.
Braga IA, Valle D 2007. Aedes aegypti: inseticidas, mecanismos de reação e resistência. Epidemiologia e serviços em saúde pública. Revista do Sistema Único de Saúde 16: 279-293.

Brogdon WG 1989. Biochemical resistance detection: an alternative to bioassay. Parasitol Today 5: 56-60.

Brogdon WG, McAllister JC 1998. Insecticide resistance and vector control. Emerg Infect Dis 4: 605-613.

Brogdon WG, McAllister JC 2004. Insecticide resistance and vector control. J Agromedicine 9: 329-345.

Carvalho RA, Azeredo-Espin AM, Torres TT 2010. Deep sequencing of New World screw-worm transcripts to discover genes involved in insecticide resistance. BMC Genomics 11: 695.

Carvalho VM, Marques RM, Lapenta AS, Machado MFPS 2003. Functional classification of esterases from leaves of Aspidosperma polyneuron M. Arg. (Apocynaceae). Genet Mol Biol 26: 195-198.

Cassanelli S, Reyes M, Rault M, Carlo Manicardi G, Sauphanor B 2006. Acetylcholinesterase mutation in an insecticide-resistant population of the codling moth Cydia pomonella (L.). Insect Biochem Mol Biol 36: 642-653.

Claudianos C, Ranson H, Johnson RM, Biswas S, Schuler MA, Berenbaum MR, Feyereisen R, Oakeshott JG 2006. A deficit of detoxification enzymes: pesticide sensitivity and environmental response in the honeybee. Insect Mol Biol 15: 22.

Coleman M, Hemingway J 2007. Insecticide resistance monitoring and evaluation in disease transmitting mosquitoes. $J$ Pest Sci 32: 69-76.

Coutinho-Abreu IV, Balbino VQ, Valenzuela JG, Sonoda IV, Rama1ho-Ortigao JM 2007. Structural characterization of acetylcholinesterase 1 from the sand fly Lutzomyia longipalpis (Diptera: Psychodidae). J Med Entomol 44: 639-650.

da-Cunha MP, Lima JBP, Brogdon WG, Moya GE, Valle D 2005. Monitoring of resistance to the pyrethroid cypermethrin in Brazilian Aedes aegypti (Diptera: Culicidae) populations collected between 2001 and 2003. Mem Inst Oswaldo Cruz 100: 441-444.

Dumas DP, Wild JR, Raushel FM 1990. Expression of Pseudomonas phosphotriesterase activity in the fall armyworm confers resistance to insecticides. Experientia 46: 729-731.

Farnsworth CA, Teese MG, Yuan G, Li Y, Scott C, Zhang X, Wu Y, Russell RJ, Oakeshott JG 2010. Esterase-based metabolic resistance to insecticides in heliothine and sopodopteran pests. $J$ Pest Sci 35: 275-289.

Field LM, Blackman RL, Tyler-Smith C, Devonshire AL 1999. Relationship between amount of esterase and gene copy number in insecticide-resistant Myzus persicae (Sulzer). Biochem J 339: 737-742.

Harel M, Kryger G, Rosenberry TL, Mallender WD, Lewis T, Fletcher RJ, Guss JM, Silman I, Sussman JL 2000. Three-dimensional structures of Drosophila melanogaster acetylcholinesterase and of its complexes with two potent inhibitors. Protein Sci 9: 1063-1072.

Healy MJ, Dumancic MM, Oakeshott JG 1991. Biochemical and physiological studies of soluble esterases from Drosophila melanogaster. Biochem Gen 29: 365-388.

Hemingway J 2000. The molecular basis of two contrasting metabolic mechanisms of insecticide resistance. Insect Biochem Mol Biol 30: 1009-1015.

Hemingway J, Hawkes NJ, McCarroll L, Ranson H 2004. The molecular basis of insecticide resistance in mosquitoes. Insect Biochem Mol Biol 34: 653-665.

Hemingway J, Hawkes NJ, Prapanthadara L, Jayawardenal KG, Ranson $H$ 1998. The role of gene splicing, gene amplification and regulation in mosquito insecticide resistance. Philos Trans $R$ Soc Lond B Biol Sci 353: 1695-1699. 
Hemingway J, Karunaratne SH 1998. Mosquito carboxylesterases: a review of the molecular biology and biochemistry of a major insecticide resistance mechanism. Med Vet Entomol 12: 1-12.

Hemingway J, Ranson H 2000. Insecticide resistance in insect vectors of human disease. Annu Rev Entomol 45: 371-391.

Hotelier T, Nègre V, Marchot P, Chatonnet A 2010. Insecticide resistance through mutations in cholinesterases or carboxylesterases: data mining in the ESTHER database. J Pest Sci 35: 315-320.

Hotelier T, Renault L, Cousin X, Negre V, Marchot P, Chatonnet A 2004. ESTHER, the database of the alpha/beta-hydrolase fold superfamily of proteins. Nucleic Acids Res 32: 145-147.

Kakani EG, Bon S, Massoulie J, Mathiopoulos KD 2011. Altered GPI modification of insect AChE improves tolerance to organophosphate insecticides. Insect Biochem Mol Biol 41:150-158.

Karve R, Lauria M, Virnig A, Xia X, Rauh BL, Moore B 2010. Evolutionary lineages and functional diversification of plant hexokinases. Mol Plant 3: 334-346.

Kelley LA, Sternberg JEM 2009. Protein structure prediction on the web: a case study using the Phyre server. Nature Protocols 4: 363-371.

Khersonsky O, Roodveldt C, Tawfik DS 2006. Enzyme promiscuity: evolutionary and mechanistic aspects. Curr Opin Chem Biol 10: 498-508.

Krejci E, Duval N, Chatonnet A, Vincens P, Massoulie J 1991. Cholinesterase-like domains in enzymes and structural proteins: functional and evolutionary relationships and identification of a catalytically essential aspartic acid. Proc Natl Acad Sci USA 88: 6647-6651.

Kwon DH, Clark JM, Lee SH 2010. Extensive gene duplication of acetylcholinesterase associated with organophosphate resistance in the two-spotted spider mite. Insect Mol Biol 19: 195-204.

Li B, Wang YH, Liu HT, Xu YX, Wei ZG, Chen YH, Shen WD 2010. Genotyping of actylcholinesterase in insects. Pest Biochem Physiol 98: 19-25.

Li CX, Dong YD, Song FL, Zhang XL, Gu WD, Zhao TY 2009. Company amplification of estalpha2/estbeta2 and correlation between esterase gene copy number and resistance to insecticides in the field Culex pipiens pallens strains collected from Beijing, China. J Med Entomol 46: 539-545.

Li X, Schuler MA, Berenbaum MR 2007. Molecular mechanisms of metabolic resistance to synthetic and natural xenobiotics. Ann Rev Entomol 52: 231-253.

Lima-Catelani AR, Ceron CR, Bicudo HE 2004. Variation of genetic expression during development, revealed by esterase patterns in Aedes aegypti (Diptera, Culicidae). Biochem Genet 42: 69-84.

Liu N, Xu Q, Li T, He L, Zhang L 2009. Permethrin resistance and target site insensitivity in the mosquito Culex quinquefasciatus in Alabama. J Med Entomol 46: 1424-1429.

Liu Z, Williamson MS, Lansdell SJ, Han Z, Denholm I, Millar NS 2006. A nicotinic acetylcholine receptor mutation (Y151S) causes reduced agonist potency to a range of neonicotinoid insecticides. J Neurochem 99: 1273-1281.

Mackness MI, Thompson HM, Hardy AR, Walker CH 1987. Distinction between 'A'-esterases and arylesterases. Biochem J 245: 293-296.

Mentlein R, Berge RK, Heymann E 1985. Identity of purified monoacylglycerol lipase, palmitoyl-CoA hydrolase and aspirin-metabolizing carboxylesterase from rat liver microsomal fractions. A comparative study with enzymes purified in different laboratories. Biochem J 232: 479-483.

Montella IR, Martins AJ, Viana-Medeiros PF, Lima JB, Braga IA, Valle D 2007. Insecticide resistance mechanisms of Brazilian Ae- des aegypti populations from 2001 to 2004. Am J Trop Med Hyg 77: 467-477.

Myers M, Richmond RC, Oakeshott JG 1988. On the origins of esterases. Mol Biol Evol 5: 113-119.

Nardini M, Dijkstra BW 1999. Alpha/beta hydrolase fold enzymes: the family keeps growing. Curr Opin Struct Biol 9: 732-737.

Nauen R 2007. Insecticide resistance in disease vectors of public health importance. Pest Manag Sci 63: 628-633.

Newcomb RD, Campbell PM, Ollis DL, Cheah E, Russell RJ, Oakeshott JG 1997. A single amino acid substitution converts a carboxylesterase to an organophosphorus hydrolase and confers insecticide resistance on a blowfly. Proc Natl Acad Sci 94: 7464-7468.

Oakeshott JG, Claudianos C, Campbell PM, Newcomb RD, Russell RJ 2005. Biochemical genetics and genomics of insect esterases. In LI Gilbert, K Latrou, SS Gill (eds.), Comprehensive molecular insect science - pharmacology, Vol 5, Elsevier, Oxford, p. 309-381.

Oakeshott JG, Claudianos C, Russell RJ, Robin GC 1999. Carboxyl/ cholinesterases: a case study of the evolution of a successful multigene family. BioEssays 21: 1031-1042.

Oakeshott JG, Horne I, Sutherland TD, Russel RJ 2003. The genomic of insecticide resistance. Genome Biol 4: 202.

Oakeshott JG, Johnson RM, Berenbaum MR, Ranson H, Cristino AS, Claudianos C 2010. Metabolic enzymes associated with xenobiotic and chemosensory responses in Nasonia vitripennis. Insect Mol Biol 19 (Suppl. 1): 147-163.

Oakeshott JG, van Papenrecht EA, Boyce TM, Healy MJ, Russell RJ 1993. Evolutionary genetics of Drosophila esterases. Genetica 90: 239-268.

Ødegard F 2000. How many species of arthropods? Erwin's estimate revised. Biol J Linnean Soc 71: 583-597.

Ollis DL, Cheah E, Cygler M, Dijkstra B, Frolow F, Franken SM, Harel M, Remington SJ, Silman I, Schrag J, Sussman JL, Verschueren KHG, Goldman A 1992. The alpha/beta hydrolase fold. Protein Eng 5: 197-211.

Polson, KA, Brogdon, WG, Rawlins SC, Chadee DD 2011. Characterization of insecticide resistance in Trinidadian strains of Aedes aegypti mosquitoes. Acta Tropica 117: 31-38.

Poupardin R, Reynaud S, Strode C, Ranson H, Vontas J, David JP 2008. Cross-induction of detoxification genes by environmental xenobiotics and insecticides in the mosquito Aedes aegypti: impact on larval tolerance to chemical insecticides. Insect Biochem Mol Biol 38: 540-551.

Punta M, Coggill PC, Eberhardt RY, Mistry J, Tate J, Boursnell C, Pang N, Forslund K, Ceric G, Clements J, Heger A, Holm L, Sonnhammer ELL, Eddy SR, Bateman A, Finn RD 2012. The Pfam protein families databases. Nucleic Acids Res 40: D290-D301.

Ramphul U, Boase T, Bass C, Okedi LM, Donnelly MJ, Muller P 2009. Insecticide resistance and its association with target-site mutations in natural populations of Anopheles gambiae from eastern Uganda. Trans R Soc Trop Med Hyg 103: 1121-1126.

Ranson H, Claudianos C, Ortelli F, Abgrall C, Hemingway J, Sharakhova MV, Unger MF, Collins FH, Feyereisen R 2002. Evolution of supergene families associated with insecticide resistance. Science 298: 179-181.

Ranson H, N'Guessan R, Lines J, Moiroux N, Nkuni Z, Corbel V 2011. Pyrethroid resistance in African anopheline mosquitoes: what are the implications for malaria control? Trends Parasitol 27: 91-98.

Raymond M, Chevillon C, Guillemaud T, Lenormand T, Pasteur N 1998. An overview of the evolution of overproduced esterases in 
the mosquito Culex pipiens. Philos Trans R Soc Lond B Biol Sci 353: 1707-1711.

Reiner E 1993. Recommendations of the IUBMB Nomenclature Committee: comments concerning classification and nomenclature of esterases hydrolysing organophosphorus compounds. Chem Biol Interact 87: 15-16.

Riaz MA, Poupardin R, Reynaud S, Strode C, Ranson H, David JP 2009. Impact of glyphosate and benzo[a]pyrene on the tolerance of mosquito larvae to chemical insecticides. Role of detoxification genes in response to xenobiotics. Aquat Toxicol 93: 61-69.

Russell RJ, Scott C, Jackson CJ, Pandey G, Taylor MC, Choppin CW, Liu J-W, Oakeshott JG 2011. The evolution of new enzyme function: lessons from xenobiotic metabolizing bacteria versus insecticide-resistant insects. Evol Applic 4: 225-248.

Saavedra-Rodriguez K, Suarez AF, Salas IF, Strode C, Ranson H, Hemingway J, Black IV WC 2011. Transcription of detoxification genes after permethrin selection in the mosquito Aedes aegypti. Insect Mol Biol online: doi: 10.1111/j.1365-2583.2011.01113.x.

Satoh T, Hosokawa M 1995. Molecular aspects of carboxylesterase isoforms in comparison with other esterases. Toxicol Let 82/83: 439-445.

Satoh T, Hosokawa M 2006. Structure, function and regulation of carboxylesterases. Chem Biol Interact 162: 195-211.

Satoh T, Taylor P, Bosron WF, Sanghani SP, Hosokawa M, La Du BN 2002. Current progress on esterases: from molecular structure to function. Drug Metab Dispos 30: 488-493.

Scanlan TS, Reid RC 1995. Evolution in action. Chem Biol 2: 71-75.

Sogorb MA, Vilanova E 2002. Enzymes involved in the detoxification of organophosphorous, carbamate and pyrethroid insecticides through hydrolysis. Toxicol Lett 128: 215-228.

Strode C, Wondji CS, David JP, Hawkes NJ, Lumjuan N, Nelson DR, Drane DR, Karunaratne SH, Hemingway J, Black WCt, Ranson $\mathrm{H}$ 2008. Genomic analysis of detoxification genes in the mosquito Aedes aegypti. Insect Biochem Mol Biol 38: 113-123.

Teese MG, Campbell PM, Scott C, Gordon KHJ, Southon A, Hovan D, Robin C, Russell RJ, Oakeshott JG. 2010. Gene identification and proteomic analysis of the esterases of the cotton bollworm, Helicoverpa armigera. Insect Biochem Mol Biol 40: 1-16.

Testa B, Kramer SD 2007. The biochemistry of drug metabolism - an introduction: part 3. Reactions of hydrolysis and their enzymes. Chem Biodivers 4: 2031-2122.

Thorpe JP 1982. The molecular clock hypothesis: biochemical evolution, genetic differentiation and systematics. Ann Rev Ecol Syst 13: $139-168$.

Thorpe JP 1983. Enzyme variation, genetic distance and evolutionary divergence in relation to levels of taxonomic separation. Systematics Association Special 24: 131-152.
Valle D, Montella IR, Ribeiro RA, Viana-Medeiros PF, Martins-Jr AJ, Lima JBP 2006. Metodologia para quantificação de atividade de enzimas relacionadas com a resistência a inseticidas em Aedes aegypti/Quantification methodology for enzyme activity related to insecticide resistance in Aedes aegypti, Fundação Oswaldo Cruz/ Secretaria de Vigilância em Saúde/Ministério da Saúde, Rio de Janeiro/Distrito Federal, 128 pp.

Van Leeuwen T, Vontas J, Tsagkarakou A, Dermauw W, Tirry L 2010. Acaricide resistance mechanisms in the two-spotted spider mite Tetranychus urticae and other important Acari: a review. Insect Biochem Mol Biol 40: 563-572.

Vaughan A, Hemingway J 1995. Mosquito carboxylesterase Est alpha 2(1) (A2). Cloning and sequence of the full-length cDNA for a major insecticide resistance gene worldwide in the mosquito Culex quinquefasciatus. J Biol Chem 270: 17044-17049.

Verger R 1997. 'Interfacial activation' of lipases: facts and artifacts. Trends in Biotechnol 15: 32-38.

Vontas J, David JP, Nikou D, Hemingway J, Christophides GK, Louis C, Ranson H 2007. Transcriptional analysis of insecticide resistance in Anopheles stephensi using cross-species microarray hybridization. Insect Mol Biol 16: 315-324.

Walker $\mathrm{CH}$ 1993. The classification of esterases which hydrolyse organophosphates: recent developments. Chem Biol Interact 87: $17-24$.

Walker CH, Mackness MI 1983. Esterases: problems of identification and classification. Biochem Pharmacol 32: 3265-3269.

Weill M, Malcolm C, Chandre F, Mogensen K, Berthomieu A, Marquine M, Raymond M 2004. The unique mutation in ace-1 giving high insecticide resistance is easily detectable in mosquito vectors. Insect Mol Biol 13: 1-7.

Whalon ME, Mota-Sanchez D, Hollingworth RM 2008. Global pesticide resistance in arthropods, CAB International, Cambridge, 208 pp.

Wheelock CE, Shan G, Ottea J 2005. Overview of carboxylesterases and their role in the metabolism of insecticides. J Pest Sci 30: 9.

Wogulis M, Wheelock CE, Kamita SG, Hinton AC, Whetstone PA, Hammock BD, Wilson DK 2006. Structural studies of a potent insect maturation inhibitor bound to the juvenile hormone esterase of Manduca sexta. Biochemistry 45: 4045-4057.

Yu QY, Lu C, Li WL, Xiang ZH, Zhang Z 2009. Annotation and expression of carboxylesterases in the silkworm, Bombyx mori. BMC Genomics 10: 553.

Zhu YC, Guo Z, Chen MS, Zhu KY, Liu XF, Scheffler B 2011. Major putative pesticide receptors, detoxification enzymes and transcriptional profile of the midgut of the tobacco budworm, Heliothis virescens (Lepidoptera: Noctuidae). J Invertebr Pathol 106: 296-307.

Zouros E, van Delden W 1982. Substrate-preference polymorphism at an esterase locus of Drosophila mojavensis. Genetics 100: 307-314. 